\title{
Interactive comment on "Establishing relationship between measured and predicted soil water characteristics using SOILWAT model in three agro-ecological zones of Nigeria" by OrevaOghene Aliku and Suarau O. Oshunsanya
}

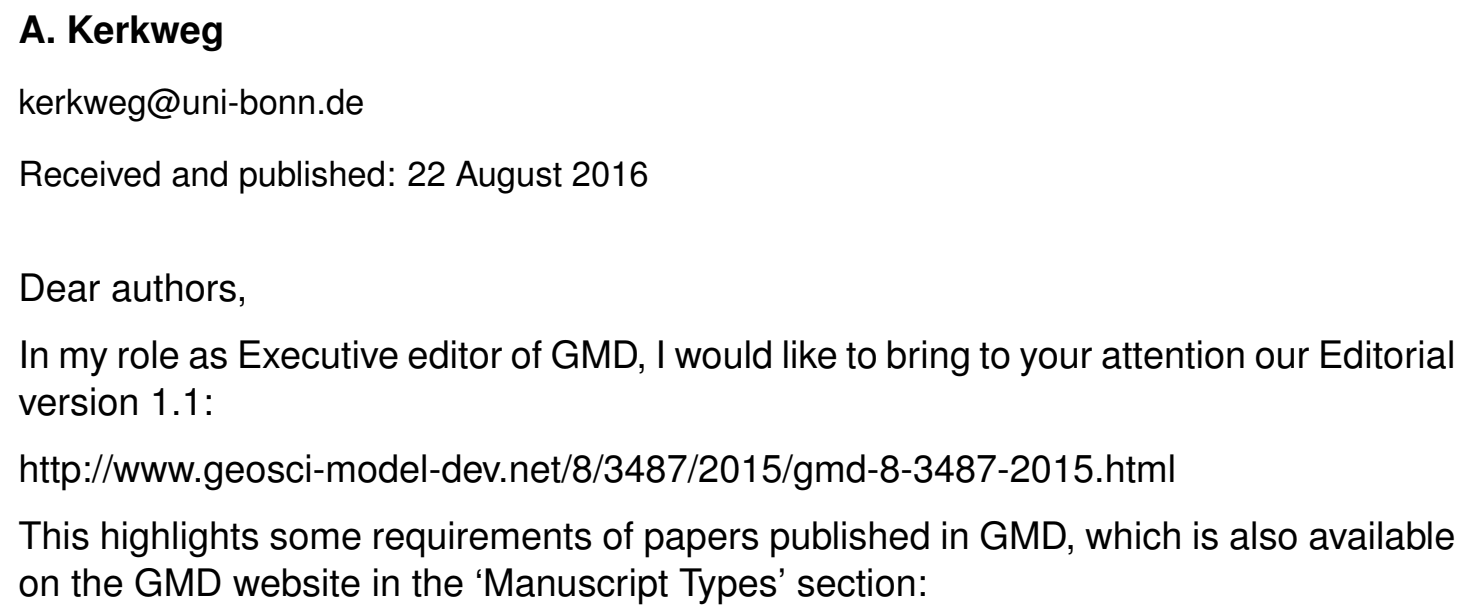

Dear authors,

In my role as Executive editor of GMD, I would like to bring to your attention our Editorial version 1.1:

http://www.geosci-model-dev.net/8/3487/2015/gmd-8-3487-2015.html

This highlights some requirements of papers published in GMD, which is also available on the GMD website in the 'Manuscript Types' section:

Printer-friendly version

Discussion paper 
http://www.geoscientific-model-development.net/submission/manuscript_types.html

In particular, please note that for your paper, the following requirement has not been met in the Discussions paper:

- "The main paper must give the model name and version number (or other unique identifier) in the title."

For a model evaluation it is important to know, which model version exactly was evaluated. Therefore, please add a version number for the SOILWAT model in the title upon your revised submission to GMD.

Yours,

Astrid Kerkweg

Interactive comment on Geosci. Model Dev. Discuss., doi:10.5194/gmd-2016-165, 2016. 